\title{
Exercise Caracity of Patients with Post-Operative Tetralogy of Fallot
}

\author{
Osahiro Takahashi, M.D., Shiho Futaki, M.D. \\ and Tetsuro Kamiya, M.D.
}

\begin{abstract}
Twenty-one patients with tetralogy of Fallot following intracardiac repair underwent a treadmill test for evaluation of their exercise capacity. They were divided into two groups according to their post-operative hemodynamic status, the good result group and the poor result group. The maximum oxygen consumption during exercise was significantly decreased in the poor result group, but that of the good result group showed no significant difference from the control group. However, the maximum heart rate in both the good and the poor result groups was significantly lower than that of the control group. Thus, the exercise tolerance in post-operative tetralogy patients was found to be within the normal range as long as their hemodynamic operative result was satisfactory, but the limited capability of increasing heart rate with exercise could present a potential problem in the long-term prognosis.
\end{abstract}

$\mathbf{T}$

HE mortality associated with intracardiac repair of tetralogy of Fallot has been reduced significantly in recent years, but relatively litte information has been available regarding the management of long-term survivors of intracardiac repair of tetralogy. Therefore, no standard recommendation exists regarding restrictions on exercise. This report summarizes results of treadmill exercise tests in patients with tetralogy of Fallot following intracardiac repair, which were performed to determine their exercise capacity.

\section{SUBJECTS AND METHOD}

A total of 21 patients with tetralogy following intracardiac repair was evaluated. Their ages ranged from 5 to 18 years $(8.86 \pm 2.11 \mathrm{y}$ : mean $\pm \mathrm{SD}$ ), and the exercise tests were performed 1 to 12 years after the surgery $(3.76 \pm$ $2.11 \mathrm{y}$.). The patients were diveded into two groups according to their post-operative hemo-

\section{Key Words:}

Tetralogy of Fallot

Intracardiac repair

Treadmill test dynamic status, which was determined by a cardiac catheterization study done within a few weeks of the treadmill test: good result group and poor result group. The poor result group included 12 patients with left ventricular ejection fraction not exceeding 0.67 , right ventricular ejection fraction not exceeding 0.5 and/or ratio of right ventricular peak systolic pressure to left ventricular peak systolic pressure greater than 0.5 . The good result group included the remaining 9 patients. A group of 96 patients with essentially normal hemodynamics served as the control. The control group consisted of patients with a history of Kawasaki disease with no evidence of coronary involvement or patients with chest pain with no evidence of organic cardiovascular pathology.

Treadmill tests were performed using CASE by Marquette with our original exercise program, in which the workload was increased progressively every three minutes. Heart rate, blood pressure and electrocardiogram were monitored during the test, and oxygen consumption was measured simultaneously with a computerized expired gas analyzing system (TMB 730 made by Tatebe Seishudo). Exercise was discontinued at the

Department of Pediatrics, National Cardiovascular Center, Osaka, Japan

Mailing address: Osahiro Takahashi, M.D., Department of Pediatrics, National Cardiovascular Center, 5-7-1 Fujishirodai, Suita, Osaka 565, Japan 
point where the patient reached complete exhaustion or at the completion of the 12-minute program.

\section{RESULTS}

The maximum heart rate ( $\max H R)$ and the maximum oxygen consumption $(\max \mathrm{VO} 2)$ in the control group, the good result group and the poor result group were $191 \pm 11,177 \pm 6$ and $177 \pm 12$ (mean $\pm \mathrm{SD}$ ) (BPM), and $43.4 \pm 7.1$, $40.3 \pm 7.8$ and $28.0 \pm 9.5$ (mean \pm SD) $(\mathrm{ml} / \mathrm{min} / \mathrm{kg})$, respectively. The max HR in both the good result group and the poor result group was significantly lower than that of the control group ( $p<0.005 ; \mathrm{p}<0.0001$, respectively). As far as the max VO2 was concerned, there was no statistically significant difference between the control group and the good result group, but that of the poor result group was significantly reduced compared to the control group $(\mathrm{p}<0.00001)$.

\section{DISCUSSION}

From these results, it appears that the exercise capacies of post-operative tetralogy patients are related to hemodynamic post-operative result. Presuming that the max VO2 is a direct indicator of the exercise capacity, then as long as the postoperative hemodynamic status is good, their exercise tolerance should be as equally good as normal persons. However, the decreased rise of heart rate in the post-operative tetralogy patients even with a good operative result is somewhat disconcerting. Post-operative tetralogy patients with a good hemodynamic results can tolerate physical exercise as well as normal peers, however a subclinical volume overload may exist in these patients, since their cardiac output must be adjusted by an increase in stroke volume in face of the limited capability to increase their heart rate with exercise. According to the result of our study on right ventricular endomyocardial biopsies in tetralogy patients, the total biopsy score in tetralogy patients was significantly higher than that in the normal control group pre-operatively $(5.3 \pm 2.5$ vs. $1.8 \pm 2.5$; $\mathrm{p}<0.001)$. In addition, patients with tetralogy had apparently abnormal myocardial histology in terms of hypertrophy, fibrosis, degenerative changes, inflammatory changes and edema. The post-operative biopsy study in the same patient group showed a further increase of the total biopsy score to $6.5 \pm 2.3$, and this change from the pre-operative score to the post-operative score was statistically significant $(p<0.001)$ ! The histological changes of their myocardium should be primarily due to the surgery itself including the effect of cardiopulmonary bypass, but the subclinical volume overload in the postoperative period might be responsible, in part, for such a histological abnormality.

Although the exercise tolerance in postoperative tetralogy patients with a good operative result has been shown to be normal at this account, potential problems may occur in terms of long-term prognosis. Many patients with postoperative congenital heart disease have restricted their activities either voluntarily or reluctantly and many patients are obviously unfit. Therefore, accurate evaluation of their exercise capacity is rather difficult, because they would stop exercise inuch before the maximum stage due to lack of patience, and their exercise capacity would tend to be rated lower than the actual value. It may be possible to increase exercise capacity by physical training, but such training could have a deteriorating effect on myocardial histology and on ventricular function, if the limited capability of increasing heart rate with exercise is indeed clinically significant.

Thus there still are many questions about the management of post-operative tetralogy patients in term of exercise allowance. More inquiries of the long-term effect of encouraging or restricting exercise in such patients are desired, in addition to further developments in less invasive surgical techniques for the intracardiac repair.

\section{REFERENCE}

1. OKAHATA $\mathrm{S}$, TANIMOTO $\mathrm{T}$, WATANABE $\mathrm{K}$, KAMIYA T, YUTANI C, NAITO Y: Right ventricular endomyocardial biopsy findings in congenital heart diseases before and after surgery. $J$ Jap Associat Thorac Surg 30 Suppl: 308, 1977 (in Japanese) 